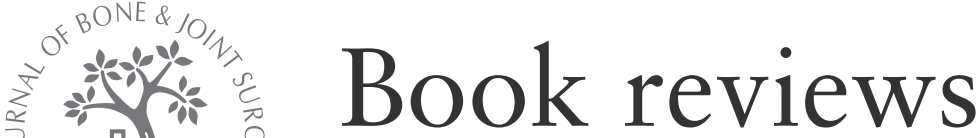

(C)2009 British Editorial Society of Bone and Joint Surgery

doi:10.1302/0301-620X.91B9.23192 \$2.00 J Bone Joint Surg [Br] 2009;91-B:1264.

\section{Hand surgery}

Edited by D. Warwick, R. Dunn, E. Melikyan, J. Vadher

Pp. 676. Oxford: Oxford University Press, 2009.

ISBN: 978-0-19-922723-5. \$79.95

There are a number of criteria by which a book may be judged. Its content takes precedence but here the problem is not what is contained in the text, but in its presentation, and for whom? Professor Warwick has approached the subject comprehensively, perhaps too comprehensively, covering every pathological condition that might occur in the upper arm and have any relevance to the hand; from lesions of the brachial plexus to Poland's syndrome.

It is a massive tome for a 'Manual' - a word that the dictionary suggests means "modest dimensions, for handy use" - no pun intended. These 700 odd pages will deform the pocket of any white coat; and each page is compressed by a punctate, often verbless prose style, which renders it very difficult to read. Of course it is not meant to be read continuously; its multiplicity of 'bullets' make it look like a volume that has been shot at with a 12 bore. Its note-form can offer little balanced emphasis on the relative importance of the items on each list, from a clinical point of view.

There can be no question as to the accuracy or the value of its surgical science. As a work of reference it is a masterpiece; ideal for an honours examination candidate. But surely it is suited to a more generous format (A4, perhaps rather than A5), and every hand unit must possess it.

M. Laurence

\section{Motion preservation surgery of the spine: advanced techniques and controversies}

Edited by J. J. Yue, R. Bertagnoli, P. C. McAfee, H. S. An

Pp. 791. Philadelphia: Saunders Elsevier, 2008. $£ 182.00$

ISBN: 978-1-4160-3994-5.

This is a big book, beautifully produced and lavishly illustrated, with over 700 pages, 97 chapters and 190 contributors. The early chapters give promise that they will establish the rationale of motion preservation as opposed to fusion, but apart from the suggestion that it is a new idea, no scientific theory is advanced as to why, after years of doing fusions - and redoing them if we thought there remained the slightest movement - we now deliberately create movement. This lack of any stated rationale for the concept in treating back pain, means that the book can provide a review of all the available implants which can be inserted into the spine to modify movement, without giving an opinion as to whether they achieve a clinically desirable objective.

The book deals with the three groups of implants covered by the term 'motion preservation'. These include disc replacements, the various posterior, pedicle-based devices that allow a restricted range of movement, and finally devices inserted between the spinous processes to provide posterior distraction, used primarily in the treatment of spinal stenosis. Many of these devices are also advocated as 'add on' procedures to a spinal fusion in order to prevent adjacent disc failure, an unproven consequence.

The great length of the book results from the multitude of devices described, with accounts of their biomechanical properties, their design and clinical application. The latter is largely unconstrained by any considerations of the rationale of their use, or of appropriate controlled trials assessing outcome. The work is a triumph of the cupidity of both surgeons and manufacturers, and the lack of any clinical constraints in the use of new devices. Innovation for the sake of innovation alone was dealt with more firmly in the past; Fernstrom (of Fernstrom balls fame) lost his post at Uddevella University and was sent north of the Arctic Circle and told not to publish anything further; and Paul Harmon, who also used a metal ball as a disc replacement, lost his Californian licence and spent two years in South America.

This is a great source of references. Everyone who is contemplating the design of a new device should read it. What it lacks in science, it partly makes up for by the provision of information. Reading it may create anxiety, even anger at times, but one would hope that it will stimulate future innovators to have a clear scientifically based objective, by which their device might be measured. Finally, any new device should be subjected to a properly controlled clinical trial before ever being released onto the open market.

R. Mulholland 